\title{
Changes in clinical patterns of Chinese patients with primary hyperparathyroidism in the past 12 years: a single-center experience
}

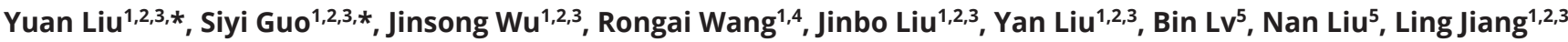 \\ and Xiaoli Zhang ${ }^{1,2,3}$ \\ ${ }^{1}$ Department of Endocrinology, Qilu Hospital of Shandong University, Jinan, China \\ ${ }^{2}$ Institute of Endocrine and Metabolic Diseases of Shandong University, Jinan, China \\ ${ }^{3}$ Key Laboratory of Endocrine and Metabolic Diseases, Shandong Province Medicine \& Health, Jinan, China \\ ${ }^{4}$ Health Management Center, The Second Affiliated Hospital of Zhejiang Chinese Medicine University, Zhejiang, China \\ ${ }^{5}$ Department of Thyroid Surgery, General Surgery, Qilu Hospital of Shandong University, Jinan, China
}

Correspondence should be addressed to X Zhang: zhangxiaoli@qiluhospital.com

*(Y Liu and S Guo contributed equally to this work)

\begin{abstract}
The clinical presentation of primary hyperparathyroidism (PHPT) differs between patients from developed and developing countries. In China, the clinical pattern has changed over the past few decades. Our aim was to elucidate general changes in the clinical characteristics of PHPT from 2010 to 2021. We enrolled 343 patients with PHPT at the Qilu Hospital of Shandong University, Jinan, China, from January 2010 to May 2021, including both surgical and non-surgical patients. Patients were divided into two subgroups, 2010-2016 (group A, $n=152$ ) and 2017-2021 (group B, $n=191$ ), based on the time span. We compared clinical manifestations and laboratory result data between these two groups. The mean patient age was $52.59 \pm 13.55$ years, and the male-to-female ratio was 1:2.54. Of the 343 patients, 183 (53.35\%) had symptomatic PHPT; bone pain, urolithiasis, and fatigue were the most common symptoms. Post-operative pathology showed that $96.20 \%$ of the patients had parathyroid adenoma, whereas $2.41 \%$ had parathyroid carcinoma. Great changes occurred between 2010 and 2021; the percentage of patients with asymptomatic PHPT (aPHPT) increased from $36.18 \%$ in group A to $54.97 \%$ in group B. Moreover, patients in group B showed significantly lower serum calcium, alkaline phosphatase, parathyroid hormone, and urinary phosphate levels but higher serum 25-hydroxyvitamin D levels than those in group A. Clinical presentations in group B were also milder. In conclusion, the clinical characteristics of Chinese PHPT patients changed dramatically from 2010 to 2021, with asymptomatic PHPT (aPHPT becoming the predominant type over the last 3 years.
\end{abstract}

Key Words

- primary hyperparathyroidism

- asymptomatic primary hyperparathyroidism

- China

- clinical features
Endocrine Connections (2021) 10, 1428-1434

\section{Introduction}

In the 1970s, due to the popularization of serum calcium (Ca) examination, a novel type of primary hyperparathyroidism (PHPT) called asymptomatic PHPT (aPHPT) emerged. It lacks the typical clinical symptoms caused by excessive secretion of parathyroid hormone (PTH). Epidemiological studies have shown that aPHPT has replaced classic symptomatic PHPT as the primary clinical type, comprising $80-95 \%$ of PHPT cases in most Western countries $(1,2,3)$. However, in developing countries such as China, India, and South Africa, symptomatic PHPT remains the primary type $(4,5,6)$.

An investigation conducted in 455 PHPT patients in Beijing from 1974 to 2009 showed that aPHPT represented only $4.6 \%$ of all cases (7). However, a trend of aPHPT

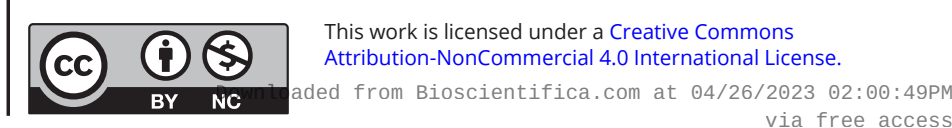


tending to predominate over symptomatic PHPT has been reported in several single-center studies in China $(4,8)$. A study conducted in Shanghai showed that the percentage of aPHPT increased from 15 to $21 \%$ during the period 2000-2006 to $42.4-52.5 \%$ during the period 2007-2010 (9). However, more recent changes in the clinical profile of PHPT in China remain unclear.

Therefore, we performed a retrospective singleinstitution study in a tertiary hospital to analyze data on sporadic PHPT and to elucidate the clinical pattern of PHPT at our hospital between 2010 and 2021.

\section{Patients and methods}

We retrospectively reviewed the medical records of PHPT patients who had been admitted to our hospital between January 2010 and May 2021. The diagnosis of PHPT was established by the presence of hypercalcemia and concomitant aberrantly elevated or inappropriately normal serum PTH level - specifically, PTH $>20$ pg $/ \mathrm{mL}$ when serum Ca was $>2.6 \mathrm{mmol} / \mathrm{L}$ (10). The diagnosis of aPHPT was based on the absence of typical symptoms or signs related to hypercalcemia; diagnoses were made incidentally during serum $\mathrm{Ca}$ examination or neck ultrasound (US). According to Silverberg \& Bilezikian (42), PHPT symptoms were defined as symptoms caused by hypercalcemia. Typical symptoms are mainly musculoskeletal (bone pain, fracture), urological (urolithiasis, polyuria, and hematuria), gastrointestinal (nausea, vomiting, and loss of appetite), and neuropsychiatric (fatigue, dizziness, and depression). Hypercalcemic crisis is defined as a serum Ca level $>3.75$ mmol/L. Secondary or tertiary hyperparathyroidism and multiple endocrine neoplasia were excluded. The study protocol was approved by the Clinical Research Ethics Committee of Qilu Hospital, Shandong University, Jinan, China. We waived informed consent due to the retrospective design of the study.

Laboratory assays included serum Ca (reference range, 2.00-2.60 mmol/L), serum phosphate (0.60-1.60 mmol/L), fasting blood glucose (FBS; 3.7-6.0 mmol/L), alkaline phosphatase (AKP; 50-135 U/L), serum creatinine (sCr; 58-133 umol/L), PTH (15-65 pg/mL; Roche Diagnostics $\mathrm{GmbH})$, and 25-hydroxyvitamin D (25(OH)D; $\geq 30 \mathrm{ng} / \mathrm{mL}$; Roche Diagnostics $\mathrm{GmbH})$. We calculated albumin (ALB)-corrected serum Ca levels (mmol/L) using the following formula:

Serum Ca concentration $=$ measured serum $\mathrm{Ca}(\mathrm{mmol} / \mathrm{L})$

$$
+(40-\operatorname{serum} \text { albumin }[\mathrm{g} / \mathrm{L}]) \times 0.02
$$

US was used to detect parathyroid nodules and kidney stones. Diagnoses of parathyroid carcinoma (PC), adenoma, cysts, and hyperplasia were confirmed by pathological examination after surgery.

We performed all statistical analyses using SPSS software version 24.0 (IBM Corp.). Normally distributed continuous data (assessed using the Kolmogorov-Smirnov test) were presented as mean \pm s.D. and analyzed using an independent sample $t$-test. Non-normally distributed data were presented as median (percentage) and analyzed using the Mann-Whitney $U$ test. We presented categorical variables as numbers ( $n$ ) with percentages (\%) and analyzed them using the chi-square test. Results were considered significant at $P<0.05$.

\section{Results}

\section{Demographics and general characteristics of patients with PHPT}

Between January 2010 and May 2021, 343 patients were diagnosed with PHPT at our hospital, including 97 men and 246 women, for a male-to-female ratio of 1:2.54 in the present study. Mean age was $52.59 \pm 13.55$ years; the age group of 50-59 years was the largest (Fig. 1).

Of the 343 patients, 183 (53.35\%) had symptomatic PHPT. The clinical manifestations of these patients are presented in Table 1. Bone pain, urolithiasis, and fatigue were the most common symptoms. Of the remaining 160 aPHPT cases, 98 were diagnosed by neck US and 62 by serum Ca examination.

In total, 290 patients with PHPT met the criteria for surgery and underwent parathyroidectomy (PTX). Postoperative pathology showed that 279 of these patients had parathyroid adenoma (96.20\%), two had hyperplasia (0.69\%), two had parathyroid cysts $(0.69 \%)$, and seven had PC (2.41\%).

\section{Changes in PHPT profiles during the period 2010-2021}

In recent years, the number of PHPT patients in our hospital has gradually increased (Fig. 2). In particular, the number of those with aPHPT has increased greatly, from 1 in 2010 to 32 in 2020. Moreover, the proportion of aPHPT cases exceeded 50\% for the first time in 2019 and rose to $58.18 \%$ in 2020 and to $82.32 \%$ within the first 5 months of 2021.

Of the total 343 patients, 55.69\% were identified in the last 5 years. We divided these 12 years into two periods,

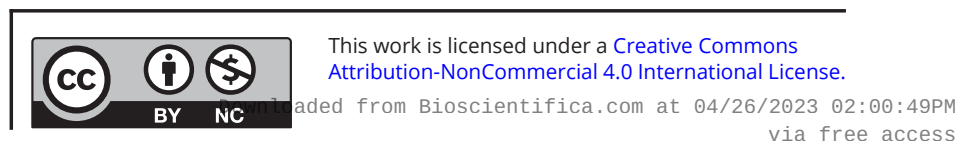




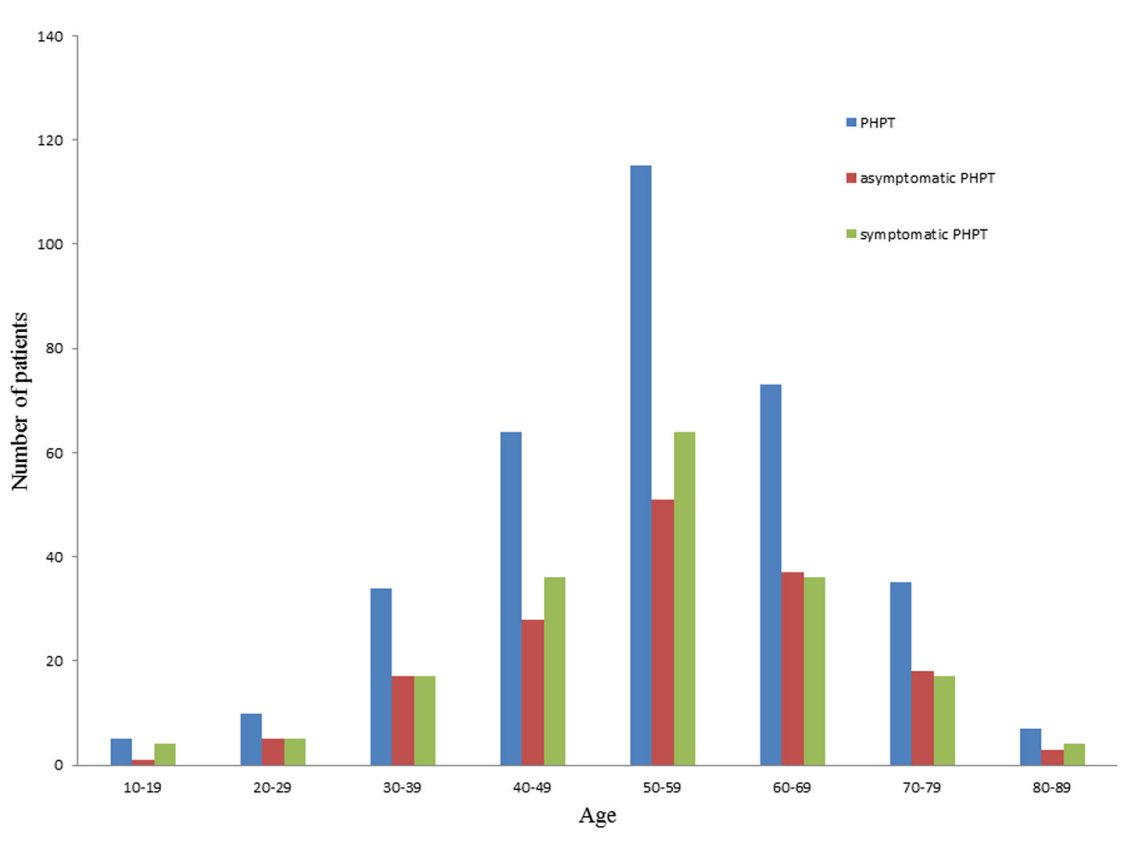

Figure 1

Age distribution of the primary hyperparathyroidism (PHPT) patients.
2010-2016 (group A) and 2017-2021 (group B), to investigate the patterns of change in PHPT patients over the past 12 years. A total of 152 and 191 patients were diagnosed with PHPT during these two time periods, respectively. No significant differences in gender were found between the two groups; however, patients in group B were older than those in group A. Compared with group A, a higher percentage of patients in group $B$ had aPHPT (54.97 vs $36.18 \% ; P<0.01$ ), but the incidence of hypercalcemic crisis was lower (7.33 vs $14.47 \% ; P<0.05$; Table 2 ). Moreover, 62 patients in group A complained of bone pain, a much higher percentage than in group B (40.79 vs 20.94\%; $P<0.01)$, and urolithiasis was also more common in group A than in group B (26.97 vs $15.71 \%$; $P<0.05)$.

Laboratory values changed greatly as well. Patients in group B had significantly lower serum Ca, AKP, PTH, and urinary phosphate levels but higher serum 25(OH)D levels than those in group A. Urinary Ca was also lower

Table 1 Clinical manifestations of the symptomatic PHPT patients $(n=183)$.

\begin{tabular}{lcc}
\hline Manifestations & Number (\%) \\
\hline Bone pain & $102(55.74)$ \\
Urolithiasis & $71(38.80)$ \\
Fatigue & $55(30.05)$ \\
Nausea and vomiting & $48(26.23)$ \\
Polydipsia and polyuria & $11(6.01)$ \\
Fracture history & $12(6.56)$ \\
Palpitation and chest distress & $8(4.37)$ \\
Constipation & $2(1.09)$ \\
Gastric ulcer & $4(2.19)$ \\
Psychiatric symptoms & $4(2.19)$ \\
\hline & \\
\hline https://ec.bioscientifica.com & (c) 2021 The authors \\
https://doi.org/10.1530/EC-21-0382 &
\end{tabular}

in group B, but this difference was not statistically significant (Table 2).

A total of 37 patients had histories of cancer when they were diagnosed with PHPT, and another five were newly diagnosed with papillary thyroid carcinoma (PTC) during pre-PTX examinations. Of these 42 patients, 27 had PTC, and diagnoses for the remainder included breast cancer $(n=4)$, lymphoma $(n=3)$, endometrial carcinoma $(n=2)$, pharyngeal cancer $(n=2)$, leukemia $(n=1)$, prostate cancer $(n=1)$, colon cancer $(n=1)$, and gastric cancer $(n=1)$. No difference in the incidence of cancer was found between groups A and B (10.53 vs 13.61\%; $P=0.41)$.

\section{Discussion}

In this retrospective single-institution study, we analyzed the data of 343 patients with PHPT to investigate changes in clinical patterns of the disease in China between 2010 and 2021. We observed a remarkable increase in the number of patients with PHPT at our center, from 7 in 2010 to 55 in 2020. Women aged 50-60 years represented the subpopulation with the highest risk, in agreement with previous studies $(3,11,12)$. The clinical spectrum of PHPT also changed greatly. Patients in group B were much older than those in group A, but group B had a higher incidence of aPHPT.

Previous studies have shown that clinical PHPT presentation differs between patients from developed countries and developing countries like China and India; patients in developing countries are younger than those in

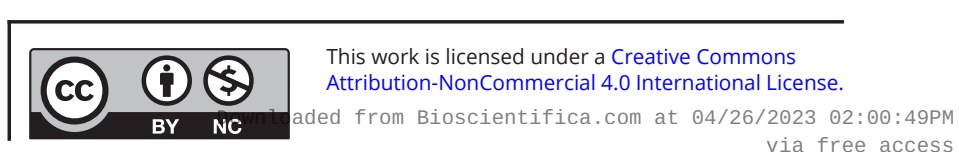




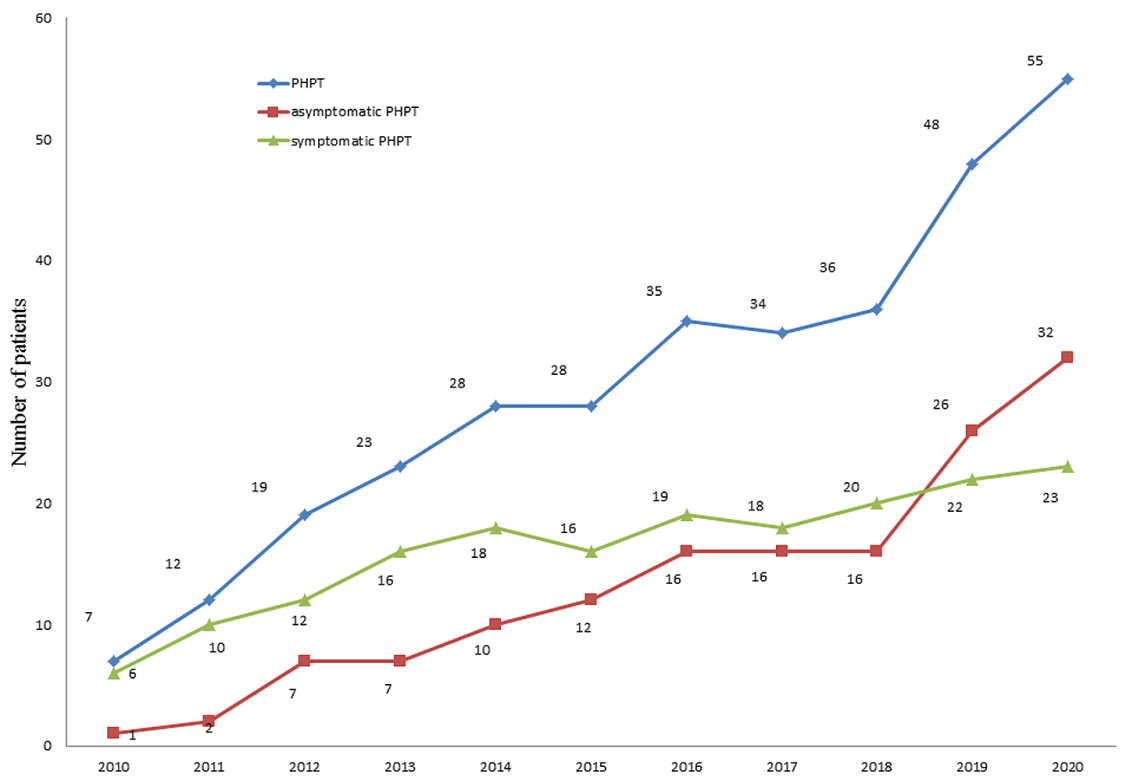

\section{Figure 2}

Number of patients with primary hyperparathyroidism (PHPT), asymptomatic PHPT (aPHPT), and symptomatic PHPT from 2010 to 2020. The number of patients with PHPT increased greatly from 2010 to 2020. developed countries $(4,13,14)$. According to the literature, 80-95\% of the PHPT patients in Western countries are aPHPT $(1,2,3,6)$, and the percentage of aPHPT has not changed substantially over the past four decades (2, 4). However, symptomatic PHPT is more prevalent in developing countries such as China and India (9, 15, 16). In a review published in 2020, 17 literatures about the presentation of PHPT in developing countries were analyzed, including India, Brazil, Turkey, and Pakistan. Results showed that the symptomatic PHPT was still the predominant type in these countries (17). Moreover, of the symptomatic PHPT patients, those in developing countries have more severe symptoms $(14,18)$. On one hand, the popularization of $\mathrm{Ca}$ and US examinations in Western countries has greatly facilitated the diagnosis of PHPT in its early stage; on the other hand, lower dietary Ca intake and vitamin D deficiency in patients from developing countries promote the secretion of PTH, leading to early onset and more severe clinical presentations $(13,19)$.

However, in recent years, there has been an increasing proportion of aPHPT patients in mainland China $(9,20)$. We summarize the literature in Table 3. Our findings revealed that the proportion of aPHPT patients increased from $3 \%$ in the 20 th century to $26.90-54.82 \%$ in the 2010 s $(13,21,22,23)$. Two studies reported on the predominance of aPHPT. Zhao et al. found that the proportion of aPHPT patients reached $52.53 \%$ at their center during the 20092010 period (9). However, this result was an anomaly;

Table 2 Comparison of clinical and biochemical characteristics between group A and group B.

\begin{tabular}{l}
\hline \\
\hline Age \\
Female/male ratio \\
aPHPT \\
Hypercalcemic crisis \\
Ca, mmol/L \\
Albumin-corrected Ca, $\mathrm{mmol} / \mathrm{L}$ \\
Phosphate, $\mathrm{mmol} / \mathrm{L}$ \\
AKP, U/L \\
PTH, pg/mL \\
25(OH)D, $\mathrm{ng} / \mathrm{mL}$ \\
Urinary Ca, $\mathrm{mmol} / 24 \mathrm{~h}$ \\
Urinary phosphate, $\mathrm{mmol} / 24 \mathrm{~h}$ \\
FBS, $\mathrm{mmol} / \mathrm{L}$ \\
Creatinine, umol/L \\
Tumor size, cm
\end{tabular}

\begin{tabular}{c}
\hline Total PHPT $(n=343)$ \\
\hline $52.59 \pm 13.55$ \\
$2.54: 1$ \\
160 \\
36 \\
$2.92(2.74,3.24)$ \\
$2.92(2.75,3.25)$ \\
$0.75 \pm 0.21$ \\
$122.00(89.00,190.00)$ \\
$288.00(144.98,737.20)$ \\
$11.63(6.87,17.52)$ \\
$10.70 \pm 5.80$ \\
$17.32(11.36,24.53)$ \\
$5.02(4.63,5.56)$ \\
$62.33 \pm 20.98$ \\
$2.00(1.50,2.58)$ \\
\hline
\end{tabular}

\begin{tabular}{c}
\hline Group A $(2010-2016, n=152)$ \\
\hline $51.18 \pm 13.31$ \\
$1.98: 1$ \\
55 \\
22 \\
$2.98(2.77,3.34)$ \\
$2.99(2.77,3.34)$ \\
$0.74 \pm 0.22$ \\
$135.00(94.25,220.50)$ \\
$395.55(198.40,1050.25)$ \\
$4.32(3.00,8.16)$ \\
$12.42 \pm 7.04$ \\
$23.40 \pm 12.92$ \\
$5.02(4.62,5.45)$ \\
$61.72 \pm 21.08$ \\
$2.00(1.50,2.50)$ \\
\hline
\end{tabular}

\begin{tabular}{c}
\hline Group B $(2017-2021, n=191)$ \\
\hline $55.50 \pm 13.48$ \\
$3.15: 1$ \\
105 \\
14 \\
$2.89(2.71,3.14)$ \\
$2.89(2.72,3.15)$ \\
$0.75 \pm 0.21$ \\
$115.00(87.00,172.00)$ \\
$208.75(121.23,564.25)$ \\
$12.74(8.52,18.28)$ \\
$9.89 \pm 4.98$ \\
$16.90(10.38,23.15)$ \\
$5.03(4.65,5.59)$ \\
$63.72 \pm 20.86$ \\
$2.00(1.50,3.00)$ \\
\hline
\end{tabular}

\begin{tabular}{c}
\hline P value \\
\hline$<0.01$ \\
0.055 \\
$<0.01$ \\
$<0.05$ \\
$<0.05$ \\
$<0.05$ \\
0.499 \\
$<0.05$ \\
$<0.01$ \\
$<0.01$ \\
0.061 \\
$<0.05$ \\
0.451 \\
0.517 \\
0.274
\end{tabular}

AKP, alkaline phosphatase; aPHPT, asymptomatic primary hyperparathyroidism; FBS, fast blood glucose; PTH, parathyroid hormone; PHPT, primary hyperparathyroidism; 25(OH)D, 25-hydroxyvitamin D.

https://ec.bioscientifica.com

https://doi.org/10.1530/EC-21-0382 (c) 2021 The authors Published by Bioscientifica Ltd

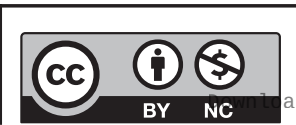

This work is licensed under a Creative Commons Attribution-NonCommercial 4.0 International License. ded from Bioscientifica.com at 04/26/2023 02:00:49PM via free access 
Table 3 Increasing trend of aPHPT in published literature.

\begin{tabular}{|c|c|c|c|c|}
\hline & Case number & City & Research period & aPHPT (\%) \\
\hline 1 & 134 & Beijing & 1958-1993 & 3 \\
\hline 2 & 455 & Beijing & 1974-2009 & 4.60 \\
\hline 3 & 59 (pediatric) & Beijing & 1975-2015 & 1.70 \\
\hline 4 & 115 & Beijing & $1975-2015$ & 10.20 \\
\hline 5 & $\begin{array}{l}31 \\
190\end{array}$ & Hong Kong & $\begin{array}{l}1983-1992 \\
1993-2002\end{array}$ & $\begin{array}{c}39.00 \\
59\end{array}$ \\
\hline 6 & $\begin{array}{l}84 \\
165\end{array}$ & Shanghai & $\begin{array}{l}2000-2006 \\
2017-2010\end{array}$ & $\begin{array}{l}19.05 \\
48.48\end{array}$ \\
\hline 7 & 457 & Shanghai & 2005-2019 & 31.30 \\
\hline 8 & 260 & Shanghai & 2005-2016 & 26.90 \\
\hline 9 & $\begin{array}{l}44 \\
153\end{array}$ & Harbin & $\begin{array}{l}2008-2012 \\
2013-2017\end{array}$ & $\begin{array}{l}15.91 \\
66.01\end{array}$ \\
\hline $10^{a}$ & $\begin{array}{l}32 \\
108\end{array}$ & Beijing & $\begin{array}{l}1 / 2010-3 / 2013 \\
4 / 2013-6 / 2016\end{array}$ & 19.29 \\
\hline 11 & 232 & Beijing & 2016-2019 & 46.10 \\
\hline 12 & $\begin{array}{l}152 \\
191\end{array}$ & Jinan & $\begin{array}{l}1 / 2010-12 / 2016 \\
1 / 2017-5 / 2021\end{array}$ & $\begin{array}{l}36.18 \\
54.97\end{array}$ \\
\hline
\end{tabular}

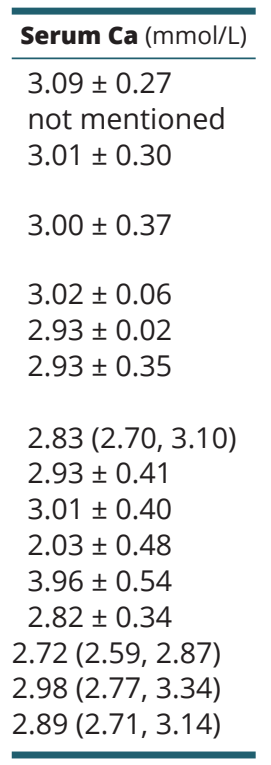

\begin{tabular}{|c|c|}
\hline Serum PTH $(\mathrm{pg} / \mathrm{mL})$ & Reference \\
\hline 21.4-fold of upper limit & 14 \\
\hline not mentioned & 7 \\
\hline $\begin{array}{l}\text { 7.69-fold of upper limit } \\
(3.13,28.29)\end{array}$ & 22 \\
\hline $\begin{array}{l}\text { 7.62-fold of upper limit } \\
(3.64,13.32)\end{array}$ & 22 \\
\hline $342 \pm 64$ & 8 \\
\hline $155 \pm 11$ & \\
\hline $402.10(103.22,2700.62)$ & 9 \\
\hline $168.35(115.30,370.98)$ & 21 \\
\hline $539.79(128.40,533.10)$ & 25 \\
\hline $1025.54 \pm 887.69$ & 26 \\
\hline $657.10 \pm 806.75$ & \\
\hline $290(94.5,2603)$ & 23 \\
\hline $193(40.6,2269)$ & \\
\hline $146.3(109.6,245.2)$ & 24 \\
\hline $395.55(198.40,1050.25)$ & The present study \\
\hline $208.75(121.23,564.25)$ & \\
\hline
\end{tabular}

aThe definition of aPHPT was different in this study. aPHPT, asymptomatic primary hyperparathyroidism; PTH, parathyroid hormone.

more recent studies conducted in the same city showed that symptomatic PHPT continued to predominate from 2010 to $2019(20,24)$. Another study conducted in Harbin, a northern city of China, showed that the percentage of aPHPT patients was $54.82 \%$ at the research team's center during the period 2008-2017 (25). However, selection bias might have occurred, as the cohort was surgically treated, and $11.17 \%$ of the patients had concomitant PTC, which greatly increases the hospitalization rate in aPHPT. In the present study, we found that aPHPT predominated at our center from 2017 to 2021, especially since 2018; the proportion of aPHPT patients increased to $54.16 \%$ in 2019 and continued to increase to $58.18 \%$ in 2020 and to $82.35 \%$ in the first 5 months of 2021 . Our study is the first to confirm aPHPT predominance in an unselected Chinese inpatient cohort.

The fast-increasing number of PHPT patients, especially aPHPT patients, mainly stems from the popularization of neck US and serum Ca screenings $(9,26)$. Our study included 160 patients with aPHPT, which was the largest cohort of aPHPT patients in China. Blood Ca screening and US examination are not only the leading reasons for the rapid increase in aPHPT patients but have also greatly affected the clinical manifestation profile of symptomatic PHPT cases. According to studies conducted before 2016, the classic symptoms of PHPT patients in China included bone pain, polyuria, fracture, and urolithiasis $(9,24)$. However, in our study and another one published in 2021 (20), bone pain, nephrolithiasis, and fatigue were the three most common symptoms, with the fracture rate declining remarkably in symptomatic PHPT patients. Previous studies have suggested that disease duration was an important factor mediating PHPT symptoms. Many symptoms such as bone pain and nephrolithiasis could be complications of longstanding mild hypercalcemia that had previously gone undetected (27). At our center, hospitalized patients were conventionally screened for serum Ca, while US was broadly performed during annual physical examinations; both tests greatly facilitated the diagnosis of PHPT at an early stage. Meanwhile, socioeconomic status (SES) is another factor that greatly influences the detection of PHPT. According to a study from India, SES critically affects clinical presentation: among higher-SES patients, the proportion of aPHPT is higher, and those with symptomatic PHPT show milder symptoms $(18,28)$. Also, as the economy of the whole society improves, the popularization of US examination greatly increases. In the present study, $30.05 \%$ of PHPT patients at our hospital complained of fatigue, which points out the need to measure serum $\mathrm{Ca}$ in patients with this complaint in order to rule out the possibility of PHPT.

PHPT is also associated with various cancers. In studies conducted in 9782 PHPT patients in Sweden, hematopoietic malignancies and breast cancer were the two most common cancers $(29,30,31)$. The high levels of PTH and 1,25-hydroxyvitamin D in PHPT patients might exert an inhibitory effect on various parameters of the immune system and favor carcinogenesis $(32,33,34)$. However, https://ec.bioscientifica.com https://doi.org/10.1530/EC-21-0382 (c) 2021 The authors Published by Bioscientifica Ltd
This work is licensed under a Creative Commons Attribution-NonCommercial 4.0 International License. ded from Bioscientifica.com at 04/26/2023 02:00:49PM via free access 
increased mitotic activity induced by hypercalcemia and elevated concentrations of angiogenic growth factors and fibroblast growth factor induced by PTH could stimulate tumor growth $(35,36,37)$. In our study, PTC was the most common cancer, and the aforementioned study conducted in Harbin also found a high incidence of PTC, $11.17 \%$ (25). One possible explanation for this phenomenon is that the popularization of neck US has increased the detection of PTC in recent years (38). Some researchers believe that PTC in PHPT cases is overdiagnosed because in PHPT patients with concomitant PTC, the tumor diameter is significantly smaller than in patients with PTC alone $(39,40)$. However, in our previous study, we found that PTC in aPHPT patients showed a higher rate of microscopic extrathyroidal invasion than PTC in the general population (41). Therefore, the relationship between these two diseases needs further investigation.

Our research had certain limitations. We performed a retrospective single-institution study, and all patients in the cohort were hospitalized. Although we included both surgical and non-surgical patients, we might have still underestimated the number of aPHPT patients. Therefore, multi-center studies with larger populations are needed to create a more comprehensive profile of PHPT in China. Also, the lack of dual-energy X-ray data for all patients before and after surgery impeded us in fully estimating the effect of PHPT on bone mineral density.

In conclusion, in this retrospective single-center study, we demonstrated the significant changes in the clinical characteristics of PHPT patients in China during the period 2010-2021. The number of patients increased greatly, while the prevalence of hypercalcemic crisis decreased. In addition, this study is the first to confirm the predominance of aPHPT in Chinese PHPT patients. Moreover, serum Ca examination and neck US were the leading reasons for these changes.

\section{Declaration of interest}

The authors declare that there is no conflict of interest that could be perceived as prejudicing the impartiality of the research reported.

\section{Funding}

This study did not receive any specific grant from any funding agency in the public, commercial, or not-for-profit sector.

\section{Author contribution statement}

Study design: Xiaoli Zhang and Ling Jiang. Study performance: Yuan Liu. Data collection: Siyi Guo, Nan Liu, and Yan Liu. Data analysis: Siyi Guo, Jinsong Wu, and Rongai Wang. Data interpretation: Xiaoli Zhang, Bin Lv, and Jinbo Liu. Manuscript drafting: Yuan Liu and Siyi Guo. Revision of manuscript content: Xiaoli Zhang and Ling Jiang. Approval of final version of manuscript: Xiaoli Zhang, Yuan Liu, and Ling Jiang. Siyi Guo and Xiaoli Zhang were responsible for the integrity of the data analysis.

\section{References}

1 Bilezikian JP \& Silverberg SJ. Clinical practice. Asymptomatic primary hyperparathyroidism. New England Journal of Medicine 2004350 1746-1751. (https://doi.org/10.1056/NEJMcp032200)

2 Griebeler ML, Kearns AE, Ryu E, Hathcock MA, Melton 3rd LJ \& Wermers RA. Secular trends in the incidence of primary hyperparathyroidism over five decades (1965-2010). Bone 201573 1-7. (https://doi.org/10.1016/j.bone.2014.12.003)

3 Wermers RA, Khosla S, Atkinson EJ, Achenbach SJ, Oberg AL, Grant CS \& Melton 3rd LJ. Incidence of primary hyperparathyroidism in Rochester, Minnesota, 1993-2001: an update on the changing epidemiology of the disease. Journal of Bone and Mineral Research 200621 171-177. (https://doi.org/10.1359/ JBMR.050910)

4 Liu JM, Cusano NE, Silva BC, Zhao L, He XY, Tao B, Sun LH, Zhao HY, Fan WW, Romano ME, et al. Primary hyperparathyroidism: a tale of two cities revisited - New York and Shanghai. Bone Research 2013 162-169. (https://doi.org/10.4248/BR201302005)

5 Paruk IM, Esterhuizen TM, Maharaj S, Pirie FJ \& Motala AA Characteristics, management and outcome of primary hyperparathyroidism in South Africa: a single-centre experience. Postgraduate Medical Journal 201389 626-631. (https://doi.org/10.1136/ postgradmedj-2012-131707)

6 Bilezikian JP, Bandeira L, Khan A \& Cusano NE. Hyperparathyroidism. Lancet 2018391 168-178. (https://doi.org/10.1016/S01406736(17)31430-7)

7 Xu S, Wang P \& Zheng Y. Clinical research of primary hyperparathyroidism. Zhonghua Yi Xue Za Zhi 200181 1453-1455.

8 Lo CY, Chan WF, Kung AW, Lam KY, Tam SC \& Lam KS. Surgical treatment for primary hyperparathyroidism in Hong Kong: changes in clinical pattern over 3 decades. Archives of Surgery 2004139 77-82; discussion 82. (https://doi.org/10.1001/archsurg.139.1.77)

9 Zhao L, Liu JM, He XY, Zhao HY, Sun LH, Tao B, Zhang MJ, Chen X, Wang WQ \& Ning G. The changing clinical patterns of primary hyperparathyroidism in Chinese patients: data from 2000 to 2010 in a single clinical center. Journal of Clinical Endocrinology and Metabolism 201398 721-728. (https://doi.org/10.1210/jc.2012-2914)

10 Walker MD \& Silverberg SJ. Primary hyperparathyroidism. Nature Reviews: Endocrinology 201814 115-125. (https://doi.org/10.1038/ nrendo.2017.104)

11 Yu N, Donnan PT, Murphy MJ \& Leese GP. Epidemiology of primary hyperparathyroidism in Tayside, Scotland, UK. Clinical Endocrinology 200971 485-493. (https://doi.org/10.1111/j.1365-2265.2008.03520.x)

12 Gasser RW. Clinical aspects of primary hyperparathyroidism: clinical manifestations, diagnosis, and therapy. Wiener Medizinische Wochenschrift 2013163 397-402. (https://doi.org/10.1007/s10354-0130235-z)

13 Bilezikian JP, Meng X, Shi Y \& Silverberg SJ. Primary hyperparathyroidism in women: a tale of two cities - New York and Beijing. International Journal of Fertility and Women's Medicine 200045 158-165.

14 Meng L, Liu S, Al-Dayyeni A, Sheng Z, Zhou Z \& Wang X. Comparison of initial clinical presentations between primary hyperparathyroidism patients from New Brunswick and Changsha. International Journal of Endocrinology 20182018 6282687. (https://doi. org/10.1155/2018/6282687)

15 Pallan S, Rahman MO \& Khan AA. Diagnosis and management of primary hyperparathyroidism. BMJ 2012344 e1013. (https://doi. org/10.1136/bmj.e1013) 
16 Marcocci C \& Cetani F. Clinical practice. Primary hyperparathyroidism. New England Journal of Medicine 2011365 2389-2397. (https://doi.org/10.1056/NEJMcp1106636)

17 Yadav SK, Johri G, Bichoo RA, Jha CK, Kintu-Luwaga R \& Mishra SK. Primary hyperparathyroidism in developing world: a systematic review on the changing clinical profile of the disease. Archives of Endocrinology and Metabolism 202064 105-110. (https://doi. org/10.20945/2359-3997000000211)

18 Parmar G \& Chadha M. The changing face of primary hyperparathyroidism. Indian Journal of Endocrinology and Metabolism 201822 299-300. (https://doi.org/10.4103/2230-8210.236781)

19 Bhadada SK, Arya AK, Mukhopadhyay S, Khadgawat R, Sukumar S, Lodha S, Singh DN, Sathya A, Singh P \& Bhansali A. Primary hyperparathyroidism: insights from the Indian PHPT registry. Journal of Bone and Mineral Metabolism 201836 238-245. (https://doi. org/10.1007/s00774-017-0833-8)

20 Lin X, Fan Y, Zhang Z \& Yue H. Clinical characteristics of primary hyperparathyroidism: 15-year experience of 457 patients in a Single Center in China. Frontiers in Endocrinology 202112 602221. (https:// doi.org/10.3389/fendo.2021.602221)

21 Wang W, Kong J, Nie M, Jiang Y, Li M, Xia W, Meng X, Xing X \& Wang O. Primary hyperparathyroidism in Chinese children and adolescents: a single-centre experience at Peking Union Medical College Hospital. Clinical Endocrinology 201787 865-873. (https://doi. org/10.1111/cen.13453)

22 Yao XA, Wei BJ, Jiang T \& Chang H. The characteristics of clinical changes in primary hyperparathyroidism in Chinese patients. Journal of Bone and Mineral Metabolism 201937 336-341. (https://doi. org/10.1007/s00774-018-0922-3)

23 Song A, Yang Y, Wang Y, Liu S, Nie M, Jiang Y, Li M, Xia W, Wang O \& Xing X. Germline GCM2 mutation screening in Chinese primary hyperparathyroidism patients. Endocrine Practice 202026 1093-1104. (https://doi.org/10.4158/EP-2020-0132)

24 Sun B, Guo B, Wu B, Kang J, Deng X, Zhang Z \& Fan Y. Characteristics, management, and outcome of primary hyperparathyroidism at a single clinical center from 2005 to 2016. Osteoporosis International 2018 29 635-642. (https://doi.org/10.1007/s00198-017-4322-7)

25 Yu Q, Liu K, Ma D, Xie C, Wu Y, Dai W \& Jiang H. Do symptoms and serum calcium levels affect the results of surgical treatment of primary hyperparathyroidism? BioMed Research International 20192019 2150159. (https://doi.org/10.1155/2019/2150159)

26 Silva BC, Cusano NE \& Bilezikian JP. Primary hyperparathyroidism. Best Practice and Research: Clinical Endocrinology and Metabolism 2018 32 593-607. (https://doi.org/10.1016/j.beem.2018.09.004)

27 Bargren AE, Repplinger D, Chen H \& Sippel RS. Can biochemical abnormalities predict symptomatology in patients with primary hyperparathyroidism? Journal of the American College of Surgeons 2011 213 410-414. (https://doi.org/10.1016/j.jamcollsurg.2011.06.401)

28 Mithal A, Kaur P, Singh VP, Sarin D \& Rao DS. Asymptomatic primary hyperparathyroidism exists in North India: retrospective data from 2 tertiary care centers. Endocrine Practice 201521 581-585. (https://doi. org/10.4158/EP14447.OR)

29 Pickard AL, Gridley G, Mellemkjae L, Johansen C, KofoedEnevoldsen A, Cantor KP \& Brinton LA. Hyperparathyroidism and subsequent cancer risk in Denmark. Cancer 200295 1611-1617. (https://doi.org/10.1002/cncr.10846)

30 Palmieri S, Roggero L, Cairoli E, Morelli V, Scillitani A, Chiodini I \& Eller-Vainicher C. Occurrence of malignant neoplasia in patients with primary hyperparathyroidism. European Journal of Internal Medicine 201743 77-82. (https://doi.org/10.1016/j.ejim.2017.06.001)

31 Ogard CG, Engholm G, Almdal TP \& Vestergaard H. Increased mortality in patients hospitalized with primary hyperparathyroidism during the period 1977-1993 in Denmark. World Journal of Surgery 200428 108-111. (https://doi.org/10.1007/s00268-003-7046-0)

32 Geara AS, Castellanos MR, Bassil C, Schuller-Levis G, Park E, Smith M, Goldman M \& Elsayegh S. Effects of parathyroid hormone on immune function. Clinical and Developmental Immunology 20102010418695. (https://doi.org/10.1155/2010/418695)

33 Tzanno-Martins C, Futata E, Jorgetti V \& Duarte AJ. Immune response in hemodialysis patients: is there any difference when low and high iPTH levels are compared? Clinical Nephrology 200054 22-29.

34 El-Fakhri N, McDevitt H, Shaikh MG, Halsey C \& Ahmed SF. Vitamin $\mathrm{D}$ and its effects on glucose homeostasis, cardiovascular function and immune function. Hormone Research in Paediatrics 201481 363-378. (https://doi.org/10.1159/000357731)

35 Jiang L, Zhang W, Wei L, Zhou Q, Yang G, Qian N, Tang Y, Gao Y \& Jiang X. Early effects of parathyroid hormone on vascularized bone regeneration and implant osseointegration in aged rats. Biomaterials 2018179 15-28. (https://doi.org/10.1016/j.biomaterials.2018.06.035)

36 Vesely D, Astl J, Matucha P, Sterzl I \& Betka J. Serum levels of angiogenic growth factors in patients with thyroid gland tumors and parathyroid adenoma. Neuro Endocrinology Letters 200324 417-419.

37 Yazici P, Mihmanli M, Bozdag E, Aygun N \& Uludag M. Incidental finding of papillary thyroid carcinoma in the patients with primary hyperparathyroidism. Eurasian Journal of Medicine 201547 194-198. (https://doi.org/10.5152/eurasianjmed.2015.119)

38 Du L, Wang Y, Sun X, Li H, Geng X, Ge M \& Zhu Y. Thyroid cancer: trends in incidence, mortality and clinical-pathological patterns in Zhejiang Province, Southeast China. BMC Cancer 201818291. (https://doi.org/10.1186/s12885-018-4081-7)

39 Cetin K, Sikar HE, Temizkan Ş, Ofluoglu CB, Ozderya A, Aydin K, Gul AE \& Kucuk HF. Does primary hyperparathyroidism have an association with thyroid papillary cancer? A retrospective cohort study. World Journal of Surgery 201943 1243-1248. (https://doi. org/10.1007/s00268-019-04920-4)

40 Vaccarella S, Franceschi S, Bray F, Wild CP, Plummer M \& Dal Maso L. Worldwide thyroid-cancer epidemic? The increasing impact of overdiagnosis. New England Journal of Medicine 2016375 614-617. (https://doi.org/10.1056/NEJMp1604412)

41 Liu Y, Guo S, Sang S, Liu J, Qi L, Lv B \& Zhang X. Differences in clinicopathological characteristics of papillary thyroid carcinoma between symptomatic and asymptomatic patients with primary hyperparathyroidism. International Journal of Endocrinology 20212021 9917694. (https://doi.org/10.1155/2021/9917694)

42 Silverberg SJ \& Bilezikian JP. Primary hyperparathyroidism. In Endocrinology: Adult and Pediatric (Seventh Edition), ch 63, pp 1105-1124. e6. Eds JL Jameson, LJ De Groot, et al. Philadelphia, PA, USA: W.B. Saunders, 2016. (https://doi.org/10.1016/B978-0-323-18907-1.00063-9)

Received in final form 9 October 2021

Accepted 14 October 2021

Accepted Manuscript published online 14 October 2021 https://ec.bioscientifica.com https://doi.org/10.1530/EC-21-0382 (c) 2021 The authors Published by Bioscientifica Ltd

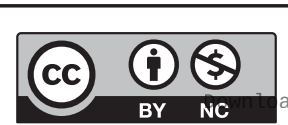

This work is licensed under a Creative Commons Attribution-NonCommercial 4.0 International License. ded from Bioscientifica com at 04/26/2023 02:00:49PM 